\title{
A CONSTRUÇÃO DA PERSONAGEM FEMININA EM MEMÓRIAS DE DUAS JOVENS ESPOSAS DE HONORÉ DE BALZAC
}

\author{
Joice Armani Galli
}

\begin{abstract}
RESUMO: Au début du XIX Xime siècle, la dualité du personnage est la dualité d'un agent social qui voit le jour. La représentation de la femme chez Balzac est le sujet de ce travail qui envisage une société et son rôle dans la construction de cet être qui est le symbole de la Modernité. Dans le roman de lettres Mémoires de deux jeunes mariées, la correspondance enregistrée par l'écriture de deux femmes révèle la discussion même de leur identité, et dans ce dialogue féminin on peut rémarqué quelques aspects de la construction du personnage qui en plus est le centre de notre exercice littéraire.
\end{abstract}

PALAVRAS-CHAVE: Personagem, Modernidade, Balzac, cartas, memórias, mulheres, feminino, literatura, Século XIX.

A produção literária de Balzac está vinculada ao estudo de uma época em que a questão social da mulher começa, ainda que timidamente, a instaurar-se na sociedade contemporânea. Por isso, a leitura da extensa obra balzaquiana ultrapassa os limites do ficcional para desvelar aí o papel da mulher por esse tempo, sobretudo se considerarmos que esse escritor dizia-se ser antes historiador de costumes a romancista. Exemplo disso é a narrativa Memórias de Duas Jovens Esposas, na qual o cruzamento entre o processo romanesco e a representação da mulher assumem conseqüências muito mais profundas que a mera retratação de uma época.

A análise desse romance, centrada nas personagens femininas, de imediato revelam-nas distintas entre si pelas vias da construção, enquanto seres fictícios, e pelas de sua representação, enquanto indivíduos sociais. Será justamente sobre essa imediata duplicidade representativa e ficcional que se vai procurar ler o presente texto. Chega-se a essa primeira consideração seguindo as

Joice Armani Galli é doutoranda em Lingüística Aplicada pela UFRGS 
palavras de Antonio Candido, segundo o qual deve-se aos recursos de caracterização utilizados em uma determinada obra a possibilidade de observar-se que: "o escritor dá a personagem, desde de logo, uma linha de coerência fixada para sempre, delimitando a curva da sua existência e a natureza de seu modo de ser"(CANDIDO, 1995, p. 59). É, pois, a partir da construção de Luísa de Chaulieu e Renata de Maucombe, as quais representam dois movimentos diferentes, que, embora desenvolvidos em direções opostas, ao contestarem-se mutuamente, apontam para a complementação de uma na outra, que se pretende abordar o romance. Memórias de Duas Jovens Esposas é o lugar da chegada de um contraste que o define como seu princípio, o texto aparentemente simples e acabado encobre sua característica primeira e essencial que é a da duplicidade de uma mesma personagem: a mulher do início do século XIX.

A recorrência à técnica do romance por cartas assegura, para Balzac, o contrato mútuo entre a forma e o conteúdo de sua história, recurso que lhe permite retratar devidamente cada uma das duas personagens sem ter a necessidade de se identificar com alguma. Esboçado como memórias essas vêem a confundir-se com a atmosfera trágica que as envolve, já que a correspondência entre as duas recémcasadas acaba, inevitavelmente, antecipando circunstâncias que já ocorreram quando do momento de sua leitura em relação a outra e assim sucessivamente.

Outro aspecto que importa destacar é o fato da construção das duas personagens dever-se ao caráter múltiplo e variado de um escritor que procura atingir um grande número de leitores, já que $A$ Comédia Humana possibilita a apreensão do que convém à natureza própria de cada leitor, em suas narrativas singulares e inéditas para a época. Por esse motivo, Memórias de Duas Jovens Esposas oferece o cenário perfeito onde se vêem ensaiados os primeiros passos de um novo tipo de representação feminina. Além da espessura de realidade que Balzac consegue apreender em sua obra ser indiscutível, pois ela é o romance da condição humana, do homem confrontado com suas próprias paixões e com as intempéries impostas pela sociedade, é o movimento das mulheres que insiste sobre a diferença dos sexos garantindo a essa história seu motor.

O fato de o casamento ter sido secularizado revela que ele é uma instituição burguesa e como tal reflete o sistema patriarcal, que, já por esse tempo, encontrava-se em processo de deterioração. A figura de Luísa é que se encarrega de despontar os primeiros indícios de alguns valores renovadores dessa sociedade e que podem ser percebidos até hoje, conforme uma das várias repreensões que sua outra parte lhe faz como: "entregas-te a desvios sancionados pelas leis; numa palavra, depravas a instituição do casamento" (BALZAC, 1989, p. 360). Na câmera lenta do processo feminino, Luísa é uma personagem que merece a descrição pormenorizada de sua construção enquanto ser social.

A não aceitação da passividade e docilidade feminina, a convicção de que ser dona de casa não era natural para ela e que a divisão entre os sexos não constituía a única base possível da harmonia social, são evidentes pela postura rebelde que assume Luísa no desenvolvimento seqüencial de sua personagem. 
Luísa foge ao padrão da época, por não aceitar que as mulheres excluídas de qualquer participação nos negócios e na vida pública devessem reinar unicamente na esfera do privado, embora seja somente por meio de uma vida secreta que a personagem consegue dialogar com a felicidade. É sua transgressão que se sobrepõe ao longo de toda a obra.

No contexto da primeira metade do século passado, os problemas do matrimônio são apresentados através da vida de duas jovens mulheres: uma, Luísa de Chaulieu, que concebe o casamento pela escolha do amor-paixão; e outra, Renata de Maucombe, que aceita docilmente seguir o caminho já demarcado pelo casamento como instituição social.

Pensionistas num convento de carmelitas, Luísa Armanda Maria de Chaulieu e Renata de Maucombe experimentam o sentimento de uma paixão exaltada como ocorre freqüentemente nas amizades entre colegas de quarto. No momento de se separar, elas juram prosseguir suas trocas de confidências por intermédio de cartas. Essa troca de correspondências se desenvolverá sobre o tema do amor.

Esse outro aspecto cultural configura-se como fato bastante representativo da época, pois, segundo História da Vida Privada, os avanços do Correio possibilitaram uma nova forma de expressão, sobretudo para as jovens mulheres: “... estando-lhes vedado ou sendo-lhes difícil o acesso ao escrever público, dedicam-se à correspondência com o prazer de uma vingança" (PERROT, 1991, p. 188)

Luísa, de origem de uma das famílias mais ilustres do reino, pretende exercer um despotismo mais que absoluto, o qual se voltará contra si própria ao final de sua vida. A busca de um amor verdadeiramente apaixonado é encontrado e sucumbido duas vezes pela protagonista de Memórias de Duas Jovens Esposas. Mas o que de fato interessa na sua busca desenfreada pela felicidade não é o estado lacônico com o qual muitas mulheres se deixariam abater, em vez disso, Luísa assume outra postura. Ela é uma personagem diferente construída não unicamente para refletir um estado de paixão folhetinesca que inundava o universo europeu da época. Mais que isso, essa personagem de Balzac é incisivamente um retrato peculiar da nova mulher que se edifica a partir de uma posição além do papel de mãe ou de amante.

Sua primeira paixão acontece com o professor de espanhol, um pobre exilado que ela irá descobrir mais tarde tratar-se do barão de Macumer. Sob sua aparência modesta, esconde-se um grande nobre da Espanha, o duque de Sória, antigo ministro, proscrito por Ferdinand VII. Luísa, que, inicialmente ignora sua verdadeira identidade, é seduzida pela nobreza dos atos desse personagem; é seduzida, também, pelos seus olhos negros e seus dentes brancos. Mas Luísa está de tal forma imbuída do tiranismo de sua classe que a manifestação de seus caprichos a tornam absurdamente insuportável para si mesma.

Após Macumer ter superado as provas de amor por ela impostas e sucumbido à sua tirânica paixão, casam-se e as flores do amor coroam o 
matrimônio. A adoração do barão por Luísa manifesta-se como um culto, ele é seu escravo e ela, na exaltação de sua paixão, mostra-se sempre mais exigente até a morte do marido.

Passado um relativo período de viuvez, Luísa procura realizar uma segunda vez seu sonho de amor apaixonado, desposando Maria-Gaston um artista sem fortuna, porém, dessa vez, será ela a escrava da paixão enlouquecida. Depois de ter sido objeto de amor no seu primeiro casamento, agora é ela a apaixonada, enclausurando o jovem esposo num tête-à-tête perpétuo na casa por ela construída somente para esse fim. O ciúme levado ao seu ápice é, na verdade, um dos sacrifícios que Gaston faz para esconder o sustento que o obriga a manter a cunhada viúva e os sobrinhos. Sob os impropérios do desentendimento Luísa suicida-se, reconhecendo muito tarde o incalculável erro de sua vida, antes da morte levá-la definitivamente.

Em contraste à vida brilhante que foi a de Luísa, plena de altos e baixos, a de Renata delineia-se pelo conformismo que sua classe social, ou seja, a burguesia ascendente, anunciava. Seu casamento e a resignação ao papel materno, de acordo com os valores da época, têm na relação marido/mulher o contrato de uma associação que visava justamente esse fim. Ao desposar Louis de L'Estorade, ou de L'Estoril conforme outras traduções, Renata aceita o casamento como a procura da felicidade, mas isenta de prazer. Totalmente dedicada à família, ela se aplica na empresa de tornar o marido um homem bem colocado na sociedade provinciana. Recria o homem escolhido, torna-o um deputado e, logo a seguir, auxilia na promoção de cargos cada vez mais importantes na esfera política de sua região. Renata de L'Estorade encontra a imensa recompensa pelos seus atos no desenvolvimento da criação dos filhos. As páginas impregnadas por seus dotes maternos parecem não ter sido escritas por um homem, material que suscitou intensa crítica para a época. A maternidade é apresentada como uma justificação do casamento, além de fazer forte referência às lições propostas pelo Visconde Luís de Bonald.

O período de mais intensa e rica produção de Balzac, situada entre os anos de 1830 e 1848, inclui o de elaboração desse romance. A mentalidade conservadora que a herança da Restauração deixou para suas políticas seguintes está afirmada pelo grande apóstolo da ideologia da época - Bonald - citado há pouco e reverenciado por Renata em suas tentativas para a recuperação da luxuosa Luísa. Sob a Monarquia de Julho (sufrágio censitário) e a Segunda República (época em que o sufrágio alcança sua universalidade), Bonald é o agente ativo de uma valorização da aristocracia. Indivíduo histórico que luta pela permanência dos valores de sua classe, Bonald chega a conseguir a supressão do divórcio autorizado desde 1792, vinte dois anos depois, período precedente à elaboração de Memórias de Duas Jovens Esposas. Entretanto, o período que se sucedeu ainda está bastante marcado nas relações familiares dos anos que deslumbram as personagens centrais do romance de Balzac. Exemplo disso é o reconhecimento que Renata faz ao declarar à amiga que enquanto essa lia Corina - famoso romance de Mme de Staël, 
cuja heroína não encontra seu lugar na sociedade, ela lia Bonald, o fundador da filosofia "tradicionalista", político e teórico da extrema direita.

$\mathrm{O}$ desejo de ter filhos expressa-se intensamente na sociedade e nas mulheres francesas do século XIX, não só pela questão da descendência, mas por ser vontade pessoal da mulher e do homem. A impossibilidade de gerar filhos acentua em Luísa sua diferença, expressa em palavras ressentidas como as que seguem, "uma mulher sem filhos é uma monstruosidade (...), somos feitas apenas para ser mães" (BALZAC, 1989, p. 327). O desacordo com a ideologia dominante estabelece a tensão textual transparente na construção dessa personagem que possui uma auto-percepção de falta para com os valores que a mentalidade da época dita como norma. As próprias palavras da personagem anunciam a punição de uma personagem que não se conforma, que não atende à norma social vigente.

Conforme História da Vida Privada, no século XIX os homens representavam o público, restando às mulheres, consequentemente, a representação do privado. Entretanto, o emblema da República Francesa é a deusa romana da Liberdade, ou seja, uma mulher que anuncia as transformações geradas pela própria revolução. A partir de um século marcado pelas transformações, essas mudanças podem vir a sinalizar uma nova era para a construção do sujeito feminino. Há, portanto, uma revolução feminina que o paratexto da introdução deste trabalho confirma. Como o próprio nome diz, esse paratexto trata de uma abertura acerca do que se verá discorrer na obra, indicando, assim, sinais de um outro consenso da então considerada representação do privado. É nesse sentido que as duas personagens, ainda que separadas, acabam por confundirem-se na malha social que as tece.

Ainda de acordo com as idéias expressas em História da Vida Privada, a casa é um dos mais importantes palcos que contextualizam essa época: "Principal teatro da vida privada, a família no século XIX fornece-lhe seus personagens e papéis principais, suas práticas e rituais, suas intrigas e conflitos. Mão invisível da sociedade civil, ela é ao mesmo tempo ninho e núcleo" (PERROT, 1991, p. 91). Tal perspectiva é igualmente constatada em Memórias de Duas Jovens Esposas, sobretudo por serem mulher e casa entendidas como sinônimos.

Embora exista a aceitação do matrimônio pautado pela relação legal, a personagem em discussão não se submete a sua lei maior: a lei patriarcal. A casa como trabalho e virtude seria o título aparentemente óbvio para Renata, no entanto, surpreende observar que, em Luísa a aceitação, e não submissão, com a qual desenvolve seu segundo casamento, demonstra, segundo a breve citação: "tornei a vida fácil e de uma vez por todas fiz-me de dona de casa, para não ser mais obrigada a sê-lo outra vez, salvo durante dez minutos todas as manhãs, com meu velho mordomo Felipe" (BALZAC, 1989, p. 344), que a casa é também espaço de trabalho e de virtude. Ela a dirige diferentemente da amiga, mas não com menos determinação e segurança. Dispensando o domínio doméstico, Luísa administra seus bens materiais como uma mulher forte que é. Em Luísa, o patrimônio de sua classe casta é, a um só tempo, necessidade econômica e afirmação simbólica. 
A versão da história da mulher do século XIX, visualizada pela coleção de referência, permite concluir que a mulher dessa época segue o tipo de Renata de Maucombe, a qual, entre o amor e a maternidade, opta pelo segundo. Tal escolha deve-se à sua perfeita modelagem em conformidade às necessidades do seio social. $\mathrm{O}$ outro tipo feminino, responsável pela possibilidade de abertura de uma nova mulher moderna, é o de Luísa de Chaulieu, que reconhece ter herdado de sua ascendência a excessiva liberdade de opiniões. A influência ao feitio de seu espírito refere-se à avó, uma das mais célebres mulheres da corte de Luís XV.

A força antagônica da mulher do século XIX é com efeito Luísa de Chaulieu, apontada desde sua saída do convento, quando relata suas primeiras incursões aos bailes, reduto social da época, à resignada Renata. Seu comentário já contém um senso crítico, demonstrado na discussão familiar que trava a propósito de seu futuro, como se pode observar no seguinte diálogo:

Pois bem _ repliquei _, os rapazes, até agora, me pareceram mais interessados do que interessantes, e mais preocupados consigo mesmos do que conosco; mas, para dizer a verdade, são muito pouco dissimulados; mudam subitamente a fisionomia que tinham tomado para nos falar, e imaginam, com certeza, que não nos sabemos servir de nossos olhos. O homem que nos fala é o amante, o que não nos fala é o marido. Quanto às moças, são tão falsas, que é impossível adivinhar-lhes o caráter por outro meio que não o de seu modo de dançar; só seu porte e seus movimentos é que não mentem. Assustou-me sobretudo a brutalidade da gente da alta roda. Quando se trata de cear, passam-se, guardadas as proporções, coisas que me dão uma imagem dos motins populares. A polidez mascara muito imperfeitamente o egoísmo geral. Eu imaginava a sociedade de outro modo. Há pouca consideração para com as mulheres, e talvez seja isso um resto das doutrinas de Bonaparte (BALZAC,1989, p. 226, grifo nosso).

Sua inconformidade em aceitar o sacrifício da mulher à família imposta pela sociedade é de todo reconhecível no comportamento profundamente psicológico e social que essa figura balzaquiana evidencia. O efeito de contraste é decisivo para a narrativa da mesma forma que sua contextualização frente à personagem, justificando um breve estudo desse elemento da ação.

A biografia de Honoré de Balzac relata que o autor costumava nomear suas obras antes de qualquer esboço escrito, pois em seu plano mental ele já o tinha idealizado por completo. Por isso é interessante observar que Memórias de Duas Jovens Esposas 1 foi inicialmente chamado Memórias de Uma Jovem Esposa. Entre o plano do livro - 1834 - e sua primeira publicação em folhetim no jornal "La Presse", em 1841, transcorreram-se aproximadamente sete anos. Baseado nesse

\footnotetext{
${ }^{1}$ Oportunamente, cabe ressaltar a observação feita por Paulo Rónai em seu livro Balzac e A Comédia Humana. São Paulo, Globo, p.30, 1993. O título em sua língua de origem Mémoires de Deux Jeunes Mariées possui em "jeunes" a função de adjetivo: condição qualitativa das esposas, ao passo que sua tradução faz modificar essencialmente a função e, portanto, o sentido. Em português, há no título a inversão do adjetivo que passa a funcionar como substantivo e esse como adjetivo.
}

252 
fato é que Paulo Rónai acredita estar na figura de Renata de Maucombe a estrutura inicial do romance.

Contrariamente à perspectiva desse crítico, considera-se como personagem mais importante, porque revolucionária e reformadora de costumes, Luísa de Chaulieu. Sua representação nesse contexto histórico é o marco de uma nova postura feminina que vem a cruzar-se perfeitamente com o plano do presente ensaio, conforme a frase de Gaston de Zélicourt, ao referir-se à obra balzaquiana ${ }^{2}$ : "Ce roman oppose la passion au fait social." (ZÉLICOURT, 1979, p. 245)

Em um meio onde se sabia ser a mulher apenas o reflexo de seu marido, a que optou pelos frutos e não pelas flores é também, à sua maneira, uma exceção à regra. Isto é, ainda que a frase-chave: "A mulher é o que faz o marido", acorde com a maioria das mulheres do início do século passado, o que acontece com Renata é exatamente o contrário. Assim, embora das duas personagens centrais essa seja a opositora da nova mulher moderna, anunciada por Luísa, ela também é, segundo suas regras e leis, a prerrogativa de uma nova esposa e mãe. Renata é quem constrói a posição do marido e adapta o lar para a ascensão burguesa desejada, de acordo com a formação religiosa de fundamento católico. Essa personagem que poderia classificar-se como personagem-função, não existe unicamente para opor a que seria a personagem-estado, mas para completarem-se reciprocamente.

Em sua obra Personagem e anti-personagem (1978, p. 35-62), Fernando Segolin ao estudar o processo de desenvolvimento desse elemento da narrativa, conceitua como personagem-função aquele que, em conformidade à teoria de Propp $^{3}$, configura-se efetivamente como um agente, cujas ações sucedem-se segundo uma certa previsibilidade que lhe confere aspecto inteiro e lógico. Essa previsibilidade encadeia-se, basicamente, sob três aspectos: o da funcionalidade, o da temporalidade e o da referencialidade.

A transformação da personagem em relação ao seu modelo tradicional, caracterizada não pelas constantes, mas pelas variantes que determinam as diferentes maneiras de contar uma mesma intriga, recebe o nome de personagemestado. Assim, essa que corresponde à Luísa, acaba por constituir sob sua forma de manifestação, um discurso preocupado em retratar um mundo visto enquanto complexo de fenômenos que devem ser medidos e avaliados.

Todavia, não se considera Renata perfeitamente classificável segundo a denominação de personagem-função, pois essa personagem não é um mero adorno do casamento, atuando como mola propulsora para a colocação do marido. Ela desenvolve sua própria luta dentro dos padrões impostos e conforme as armas de que dispõe, questão que se pode observar na seguinte passagem: "A certeza de

${ }^{2}$ ZÉLICOURT, Gaston de. Le monde de la comédie humaine - clefs pour l'oeuvre romanesque de Balzac. Paris, Seghers, 1979.

${ }^{3} \mathrm{Na}$ diacronia crítica sobre a personagem, é a partir do formalismo russo que Fernando Segolin constitui as bases de sua tese apoiando-se, especialmente, na Morfologia do Conto proposta por Vladimir Propp, cujo núcleo sustenta-se em predicados de ação conforme cada função determinada. 
seguir por um caminho traçado convém igualmente ao meu espírito e ao meu caráter" (BALZAC, 1989, p. 232). E mais adiante: "Nascemos favorecidas, podemos escolher entre o amor e a maternidade. (...) Permanecendo na solidão, uma mulher nunca se torna pronvinciana, conserva-se o que é" (BALZAC, 1989, p. 233).

O presente enfoque é ratificado quando essa afirma à Luísa que: "se o mando não está nas mãos da mulher, o casamento se torna dentro em pouco insuportável, a mulher deve então ter as seduções de uma amante e as qualidades de uma esposa" (BALZAC, 1989, p. 247). O que justifica a incorreta classificação caso se queira denominá-la uma personagem-função.

A construção da personagem Renata sugere a possibilidade de residir aí o fato de o romance ter inicialmente recebido um título singular. Parece ter havido uma matriz primeira que, sucumbida pela força da progressão romanesca, acabou por se duplicar. Aqui, o problema da composição da personagem passa a ser também um problema de distribuição, atentado para o cuidado ao nomear exclusivamente uma ou outra como protagonistas, já que ambas o são. A leitura do romance, ou melhor, a passagem de uma confidente para a outra realiza-se na base do desequilíbrio interno próprio da constituição de cada uma. Nesse sentido, devese destacar que curiosamente essas duas personagens não figuram em nenhum outro romance da grande obra balzaquiana: elles jetten donc ici, et ici seulement, tout leur éclat. (MICHEL, 1979, p. 19)

$\mathrm{O}$ contraponto à definição perfeita de Luísa como personagem-estado faznos recorrer mais uma vez a Fernando Segolin. Tal justeza deve-se ao fato da narrativa moderna formular-se nas tendências desmistificadoras em relação a uma tradição narrativa, assim, encontra-se a construção de personagens inacabadas, a construção de personagens que não se caracterizam definitivamente em virtude do incompleto de sua esfera de funções.

Portanto, a impossibilidade de classificação de Renata, segundo a proposta desse teórico, indica a abertura de sua construção ficcional, ou seja, sua não completude nesse aspecto, pois já vimos que como representação ela não é de todo expurgável, aponta a necessidade de desdobramento da personagem em sua elaboração nesse romance. Ainda que a definição personagem-estado identifiquese com Luísa, há de se reconhecer que entre essas duas personagens acontece a reunião da disparidade que seria, em seu núcleo, uma única representação social, que, por força dos artifícios narrativos tem de se apresentar sob a forma de duas personagens aparentemente diversas. Algumas frases da obra de Balzac apontam para a similaridade do que seria a origem unificada de ambas, conforme o que declara Renata para Luísa: "É bem possível que ambas estejamos em erro e tenhamos razão, e possivelmente a sociedade nos vende muito caro os nossos enfeites, os nossos títulos e os nossos filhos!" (BALZAC, 1989, p. 263) Ou de acordo a outra passagem posterior, da mesma para a mesma: “..., é que tu me afiguras uma outra eu mesma" (BALZAC, 1989, p. 321). 
Dessa forma, a mulher está marcada pela sua condição social ao ponto de essa estar definitivamente apegada e até encerrada nela como se pode observar em Renata, a qual se apresenta como um ser íntegro caracterizado pelos traços facilmente delimitáveis de sua conduta como personagem. Ao passo que, Luísa, construída nas bases de um ser complicado que não se esgota em marcas definitivas, mas que possui, conforme Antonio Candido "certos traços profundos, de onde pode jorrar a cada instante o desconhecido e o mistério" (CANDIDO, 1991, p.72), atitudes sobretudo reconhecíveis em suas manifestações amorosas. Segundo as palavras de Luísa: "Há não sei que apetite em mim para as coisas desconhecidas ou, se quiseres, proibidas, que me inquieta e me revela, no meu íntimo, um combate entre as leis das sociedades e as da natureza" (BALZAC, 1989, p. 270). A perspectiva reafirmada pelo crítico, garante o reconhecimento de que a luta de Luísa não é episódica, espontânea, ou decidida por outros, mas é necessariamente determinada pelo conflito interno dessa personagem, que contrária ao modelo materno de Renata, embate-se, ao longo de toda a narrativa, em sua constituição como ser social que se faz refletir em ser de ficção.

Acrescente-se também o acordo do meio em relação à sua desenvoltura. No texto de Memórias... há, segundo a nomenclatura de Philippe Hamon, uma espécie de "metonímia narrativa", isto é, o cenário pela personagem: Luísa - os salões parisienses - e Renata - a natureza Provençal - , recurso que o estudioso aponta como um traço característico dos autores realistas. O caminho que cada uma opta por seguir é, embora com a mesma formação, distinto, contribuindo para que ao final, ambas se encontrem em planos peculiares a cada uma. Assim, a natureza dada no início do romance é o cenário diante do qual evoluem individualmente duas jovens que, pela afinidade de idéias, comprometem-se no juramento de eterna amizade. A construção do conflito e do caráter extremo de cada uma dessas personagens revela o quanto sua representação ultrapassa os limites de uma simples imitação da realidade. Daí que Memórias de Duas Jovens Esposas apresente-se como um romance rico tanto em termos de representação do social quanto ao nível do empreendimento romanesco.

Assim, o movimento do romance é sublinhado principalmente pela combinação das duas personagens centrais que se digladiam mutuamente, mas que se acordam em determinados momentos conforme o jogo fictício de que fazem parte. Dessa forma, Luísa sucumbe à mentalidade da época somente ao fim do romance por não lhe apresentar outra saída, confessando a Renata:

Minha vida restringiu-se, ao passo que a tua aumentou, irradiou. O amor é profundamente egoísta, enquanto a maternidade tende a multiplicar nossos sentimentos. (...) Cumpriste sensatamente as leis da vida social, ao passo que eu estou à margem de tudo (BALZAC, 1989, p. 358).

Portanto, a construção da personagem Luísa, a qual não se deixou cegar pelo hábito adquirido de ver em todo o lado apenas aquilo que a sua educação a habituou a enxergar lhe é caracteristicamente distinto. A conduta de Renata de L'Estorade é o estigma da maioria das mulheres francesas da época, daí tornar-se 
eminentemente previsível seu papel na narrativa, na medida em que essa personagem já está predeterminada nas suas grandes linhas por uma História prévia escrita e fixada. Enquanto Luísa de Chaulieu aponta uma nova representação da mulher, pois seu caráter rebelde e inconformado são aspectos percucientes tanto para sua configuração social quanto para sua constituição de ser ficcional.

Tal aspecto faz com que se mencione novamente Philippe Hamon, o qual afirma ser "todo o signo definido por "restrições seletivas", isto é, pelo conjunto de regras que limitam as suas possibilidades de combinação com outros signos. Essas regras podem ser de vários tipos: lingüísticas, lógicas ou ideológicas. (HAMON, 1976, p.107) A regra sobre a ideologia é a que se coaduna com o presente texto, por ser o tipo de restrição seletiva que se define como a filtragem de certos códigos culturais, os quais limitam a capacidade teórica do modelo e impõem ao narrador uma série de restrições prévias. Sob esse enfoque, tal consideração pode enquadrar Renata, mas não Luísa, sinal que lhe confere marca definitiva de distinção. Em Memórias de Duas Jovens Esposas, a construção de Luísa demonstra ultrapassar os limites do previsível, de acordo com esse terceiro tipo proposto por Hamon. A liberdade com a qual a personagem conquista seu desenvolvimento na trama só encontra fim na morte, essa é a única saída possível para finalizar sua narrativa de ser ficcional e de ser social, porque Luísa não chegando a ser o tipo daquelas mulheres que representam o genérico de sua condição é uma singularidade destacada de seu sexo. Assim, as manifestações de Luísa nascem do próprio desvio intrínseco à sua construção, o que assegura sua particularidade e poder nessa narrativa balzaquiana.

Somente a visão perspicaz de Balzac poderia retratar os caminhos paralelos de duas mulheres diferentes como Renata e Luísa. A insubordinação da última é sutilmente apontada, deixando a construção e conseguinte leitura da personagem realizar-se por si própria. No romance, onde destinos comuns desenrolam-se em plena sociedade moderna, a visão não é outra que a de uma ótica em transparência, não é outra que a de um olhar que carrega de significação insólita os seres, os objetos, os acontecimentos deixados em seu lugar de costume e em uma coerência do cotidiano que merece maior atenção. Em Memórias de Duas Jovens Esposas pode-se realizar uma leitura profunda da construção feminina sob a ótica de um escritor inserido em valores patriarcais. Tem-se assim o cenário de uma época que retrata a relação tensa, ambivalente e dicotômica da personagem mulher enquanto ser de ficção, mas particularmente como indivíduo social. E que nos possibilita reconhecer no presente romance um texto legível não somente para a sociedade da época, mas principalmente para a atual, já que as questões trabalhadas a partir dessas duas personagens femininas são questões sociais pertinentes para os tempos atuais.

Luísa por estar circunscrita a um meio social burguês, afirma a idéia desenvolvida no presente trabalho, pois sua morte final acaba configurando-se como uma punição pela sua duplicidade. O que permanece é o lado conformista e positivo projetado na personagem que é seu duplo. Renata é a que sobrevive, pois 
tem de negar seu duplo pelo fim trágico, já que sua função é a de fixar o feminino adequado, valorizado pela sociedade da época. Assim, dessa face do Dever que equivale à Razão, como Renata mesmo afirma na página 314, há de sucumbir à Imaginação - a face do louco Amor de Luísa, a qual em seu leito de morte, reduz definitivamente ambas para um único ser de ficção, ao declarar: "Deixei-me prender nas redes do meu amor, como uma corça que se estrangula ao se impacientar por se ver presa: das duas sou eu a corça... e muito selvagem" (BALZAC, 1989, p. 373).

Portanto, a homologia entre o universo histórico e o do romance não se realiza unicamente ao nível dos elementos particulares, mas também ao nível do sistema pelo qual opera o escritor: é o sistema romanesco, em seu conjunto, que produz um efeito de realidade. O tipo social tornado personagem, apesar de largamente representativo, não preenche, contudo, de modo exato, o papel de uma generalidade: Luísa não é individualizada somente por um nome ou pelo pormenor de seu desenvolvimento na intriga, mas pelas relações que mantém com as outras personagens que, principalmente como mulheres, são personagens típicas igualmente representativas e, no entanto, distintas, que lhe dão lugar, e lugar especial, nesse romance de Honoré de Balzac.

\section{BIBLIOGRAFIA}

BALZAC, Honoré de. A comédia humana. v. 1,Rio de Janeiro, Globo, 1989. . Mémoires de deux jeunes mariées. Paris, Garnier-Flammarion, 1979.

BÉGUIN, Albert. Balzac lu et relu. Paris, Seuil, 1965.

CANDIDO, Antonio et al. A personagem de ficção. São Paulo, Perspectiva, 1987.

HAMON, Philippe. Para um estatuto semiológico da personagem. In: SEIXO, Maria Alzira (org) Categorias da narrativa. Lisboa, Arcádia, 1976.

MICHEL, Arlette. Chronologie, introduction et archives de l'oeuvre par A. M. IN.: Mémoires de deux jeunes mariées. Paris, Flammarion, 1979.

PERROT, Michelle. História da vida privada: da Revolução Francesa à Primeira Guerra. v. 4, São Paulo, Companhia das Letras, 1991.

RÓNAI, Paulo. Balzac e a comédia humana. São Paulo, Globo, 1993.

SEGOLIN, Fernando. Personagem e anti-personagem. São Paulo, Cortez \& Moraes, 1978.

ZÉLICOURT, Gaston. Le monde de la comédie humaine. Paris, Seghers, 1979. 